\title{
RETRACTED ARTICLE: The "Strong" Versus "Weak" Premise of Stakeholder Legitimacy and the Rhetorical Perspective of Diffusion
}

\author{
Eugene Z. Geh
}

Received: 13 February 2012/Accepted: 10 March 2012/Published online: 25 March 2012

(C) Springer Science+Business Media B.V. 2013

The Editors and publisher regret to report that the paper published by Eugene Z. Geh as "The 'Strong' versus 'weak' premise of stakeholder legitimacy and the rhetorical perspective of diffusion" in the Journal of Business Ethics Online First, 25 March 2012, doi:10.1007/s10551-0121281-y includes several passages (about $16 \%$ ) that duplicated passages published earlier by Sandy Edward Green as "A rhetorical theory of diffusion" in the Academy of Management Review (2004), 29(4):653-669. This is a violation of publication ethics which according to the Springer Policy on Publishing Integrity warrants a retraction of the article and a notice to this effect to be published in the journal. 